\title{
Fluvial Suspended Sediment Transfer and Lacustrine Sedimentation of Recent Flood Turbidites in Proglacial Eklutna Lake, Western
}

\section{Chugach Mountains, Alaska}

\author{
Erik Schiefer ${ }^{1}$, Jason Geck ${ }^{2}$, Johnse Ostman ${ }^{2}$, Nicholas McKay ${ }^{1}$, Nore Praet ${ }^{3}$, Michael \\ Loso $^{4}$, and Darrell Kaufman ${ }^{1}$ \\ ${ }^{1}$ Northern Arizona University \\ ${ }^{2}$ Alaska Pacific University \\ ${ }^{3}$ Ghent University \\ ${ }^{4}$ National Park Service Alaska Region
}

June 22, 2021

\begin{abstract}
Suspended sediment delivery and deposition in proglacial lakes is generally sensitive to a wide range of hydrometeorologic and geomorphic controls. High discharge conditions are of particular importance in many glaciolacustrine records, with individual floods potentially recorded as distinctive turbidites. We used an extensive network of surface sediment cores and hydroclimatic monitoring data to analyze recent flood turbidites and associated sediment transfer controls over instrumental periods at Eklutna Lake, western Chugach Mountains, Alaska. Close to a decade of fluvial data from primary catchment tributaries show a dominating influence of discharge on sediment delivery, with various interconnections with other related hydroclimatic controls. Multivariate fluvial models highlight and help quantify some complexities in sediment transfer, including intra-annual variations, meteorological controls, and the influence of subcatchment glacierization. Sediments deposited in Eklutna Lake during the last half century are discontinuously varved and contain multiple distinctive turbidites. Over a 30-year period of stratigraphic calibration, we correlate the four thickest flood turbidites $(1989,1995,2006,2012)$ to specific regional storms. The studied turbidites correlate with late-summer and early-autumn rainstorms with a magnitude of relatively instantaneous sedimentation 3 to 15 times greater than annual background accumulation. Our network of sediment core data captured the broad extent and sediment variability among the study turbidites and background sediment yield. Within-lake spatial modelling of deposition quantifies variable rates of downlake thinning and sediment focusing effects, and highlights especially large differences between the thickest flood turbidites and background sedimentation. This we primarily relate to strongly contrasting dispersion processes controlled by inflow current strength and turbidity. Sediment delivery is of interest for this catchment because of reservoir and water supply operations. Furthermore, although smaller floods may not be consistently represented, the lake likely contains a valuable proxy record of regional flooding proximal to major population centers of south-central Alaska including Anchorage.
\end{abstract}

\section{Hosted file}

Eklutna Lake Sed paper.docx available at https://authorea.com/users/293919/articles/527231fluvial-suspended-sediment-transfer-and-lacustrine-sedimentation-of-recent-floodturbidites-in-proglacial-eklutna-lake-western-chugach-mountains-alaska 
a)

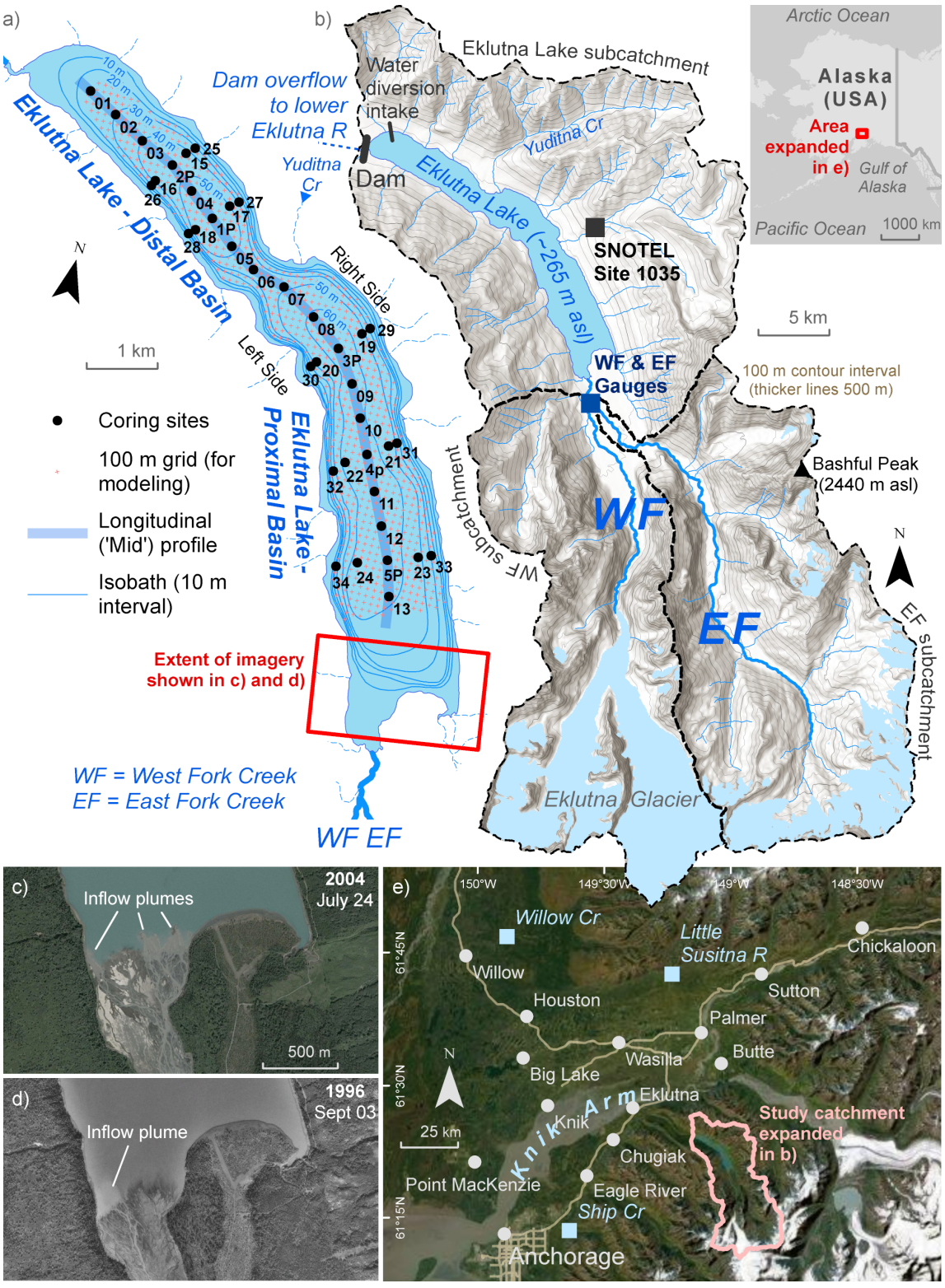



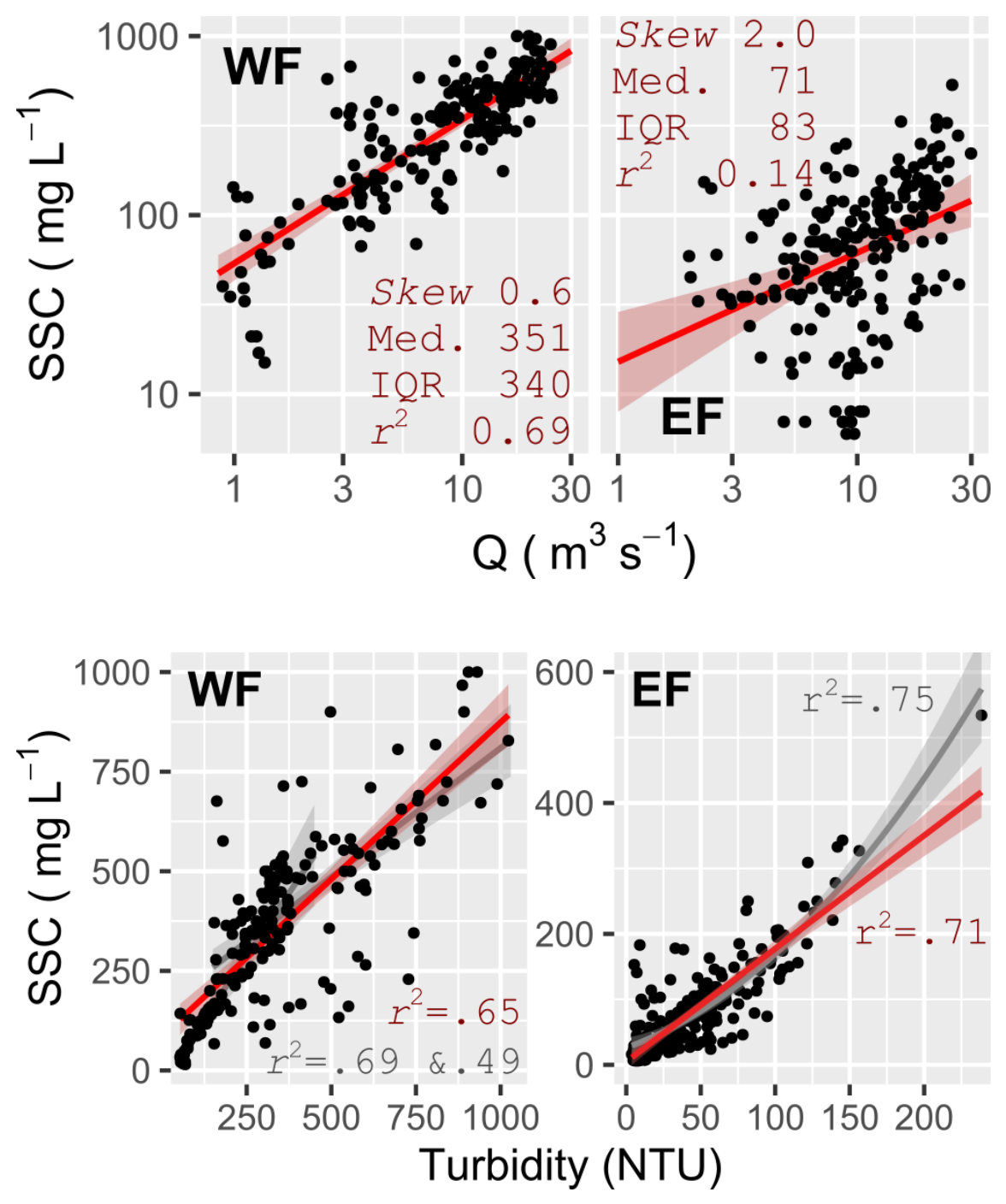

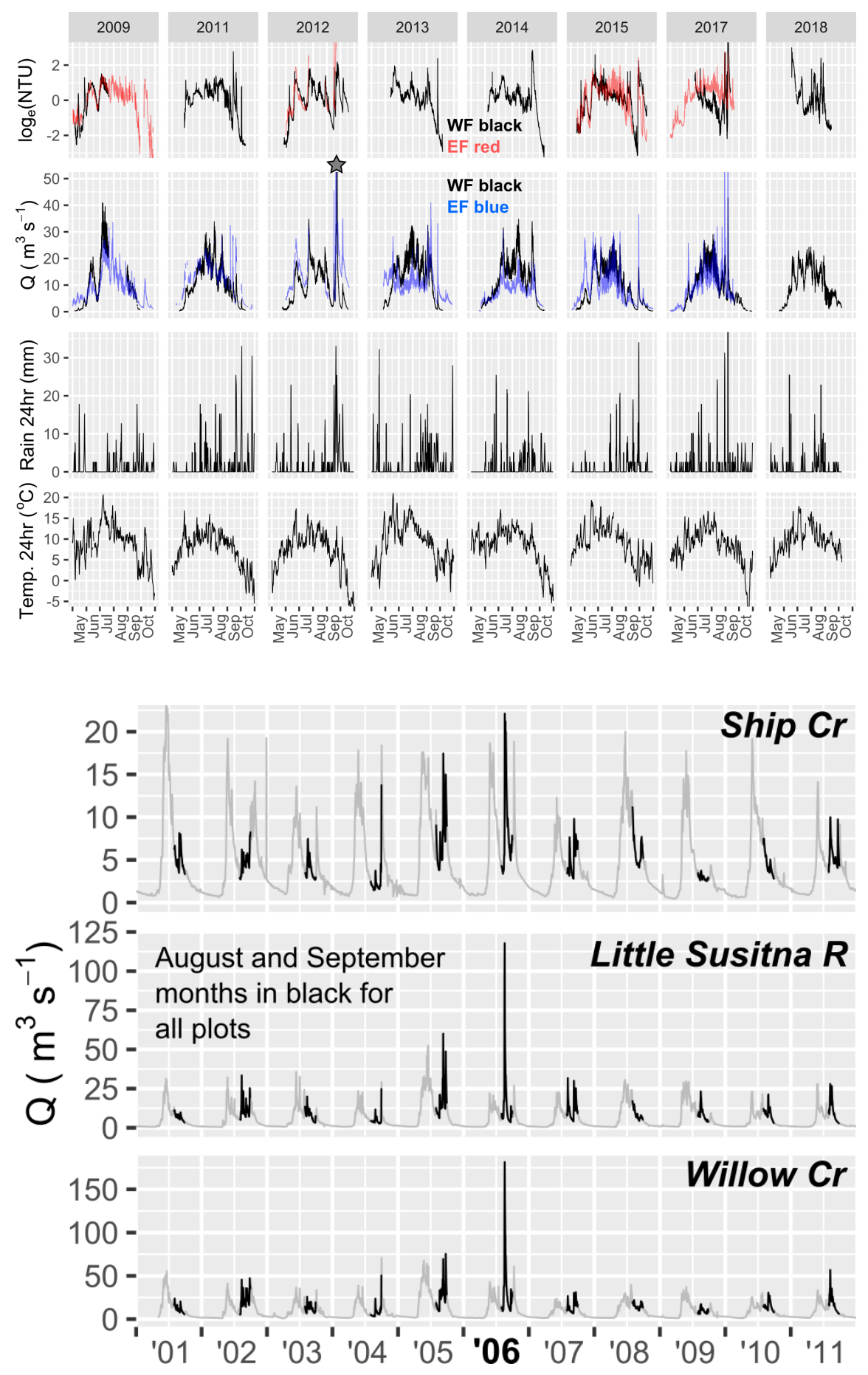


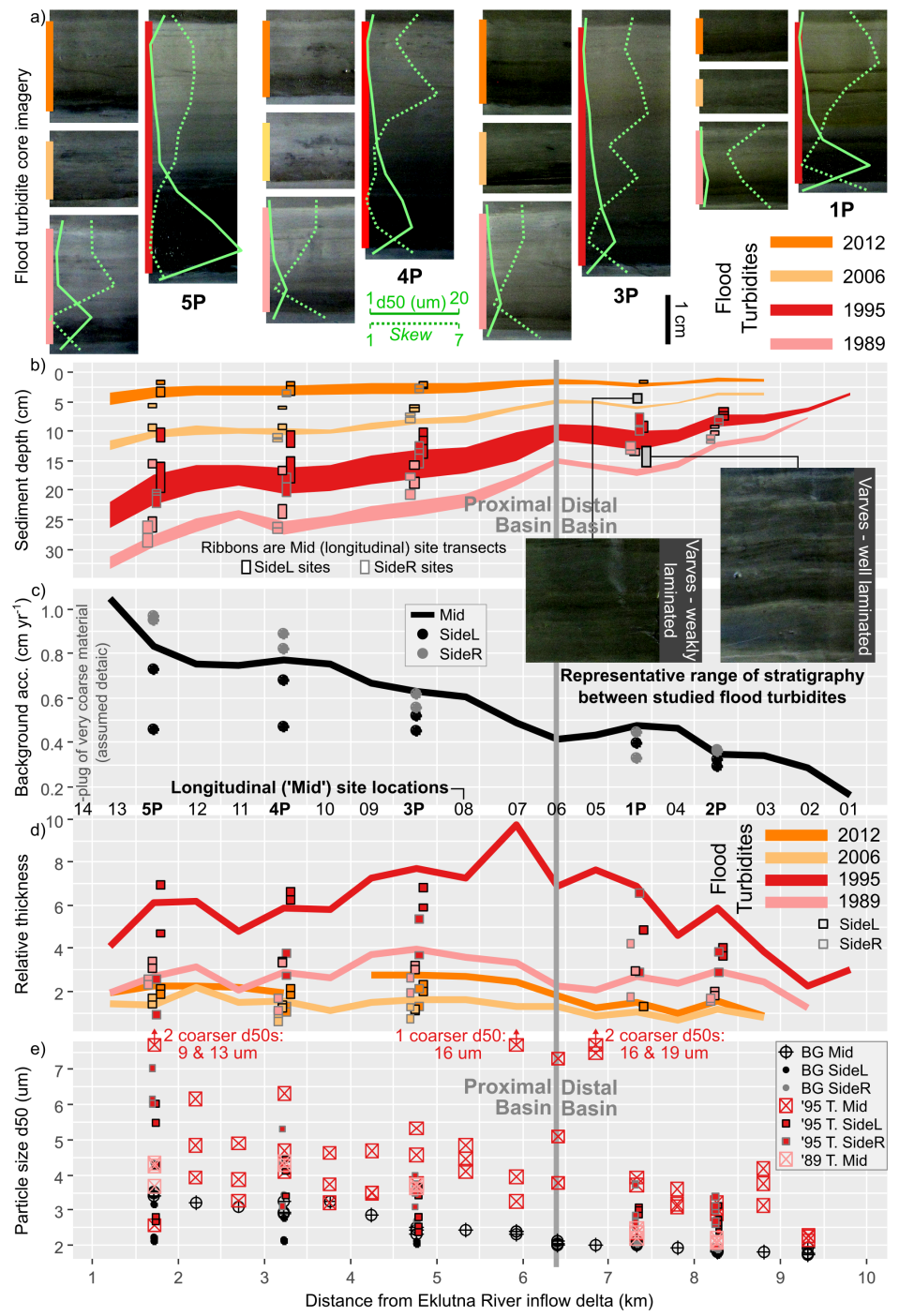




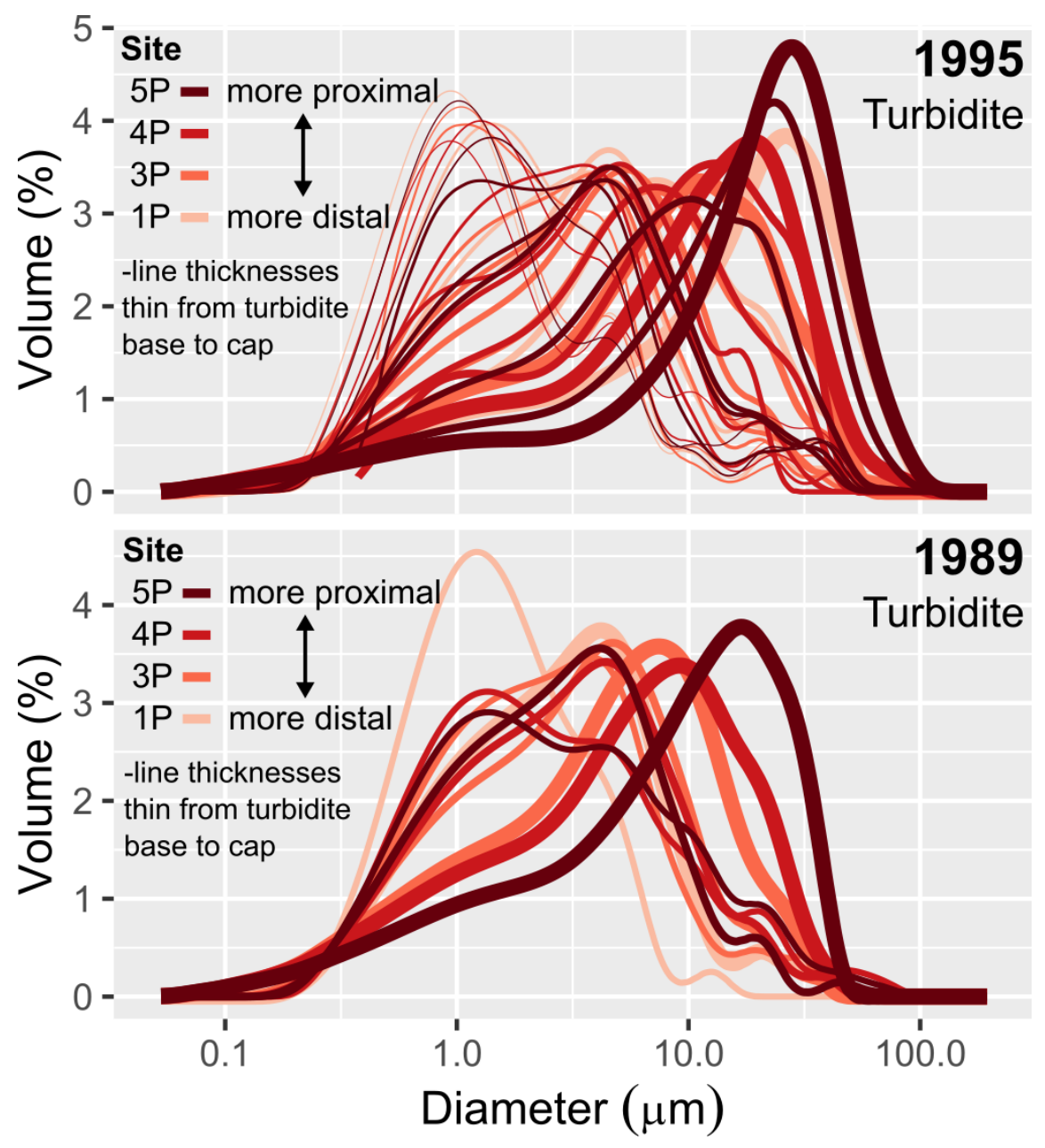



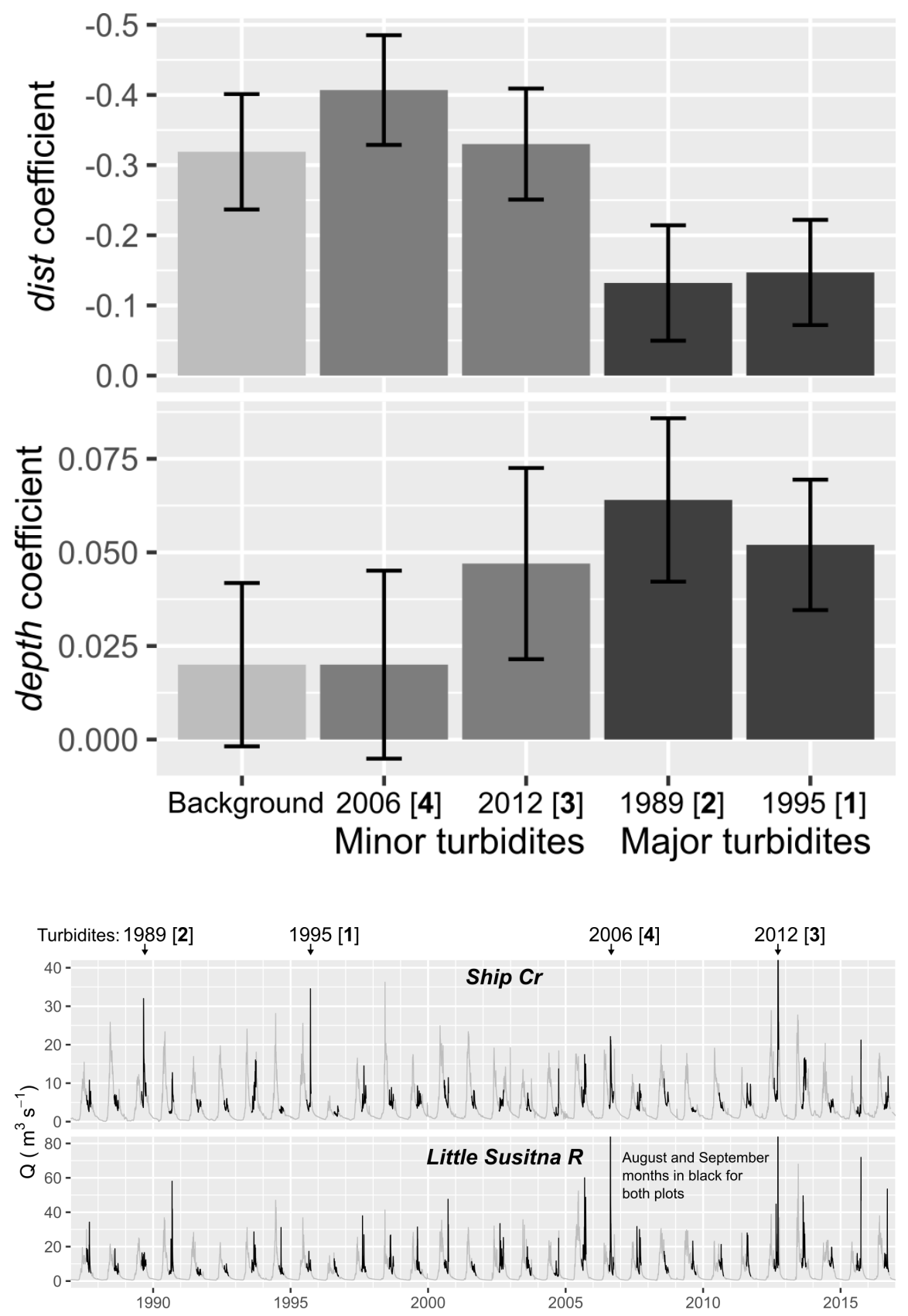